Research Article

\title{
Welfare Comparison of Leader-Follower Models in a Mixed Duopoly
}

\author{
Aiyuan Tao, ${ }^{1}$ Yingjun $\mathrm{Zhu}^{2}$ and Xiangqing $\mathrm{Zou}^{3}$ \\ ${ }^{1}$ School of Mathematics and Information Science, Shanghai Lixin University of Commerce, Shanghai 201620, China \\ ${ }^{2}$ Accounting Research Institute, Shanghai Lixin University of Commerce, China \\ ${ }^{3}$ School of Accounting and Finance, Shanghai Lixin University of Commerce, China
}

Correspondence should be addressed to Aiyuan Tao; taoaiyuan@126.com

Received 9 September 2013; Accepted 22 October 2013

Academic Editor: X. Henry Wang

Copyright (C) 2013 Aiyuan Tao et al. This is an open access article distributed under the Creative Commons Attribution License, which permits unrestricted use, distribution, and reproduction in any medium, provided the original work is properly cited.

In the standard leader-follower duopoly models with otherwise symmetric firms, the market outcome and total welfare are the same whichever firm is the leader. This paper studies and compares total welfare in a sequential-move mixed duopoly when either the public firm or the private firm acts as the leader. It is found that the fact that which firm is the leader affects total welfare and that whether firms compete in quantity or price also affects the optimal choice of market leader.

\section{Introduction}

A mixed oligopoly is one in which private and public (or semipublic) firms coexist. Casual empiricism suggests that there are many mixed oligopolies in the real economies of the world, especially in less than fully developed and recently developed economies. Theoretically, many papers have been written on this topic. The sizable literature on mixed oligopolies dates back to Merril and Schneider [1]. More recent contributions are Matsumura [2] and Matsumura and Ogawa [6] See De Fraja and Delbono [3] for a survey of the early literature. These papers have investigated a variety of issues related to mixed oligopolies.

While both simultaneous- and sequential-move models are commonly adopted in the study of purely private oligopolies, with the most well-studied simultaneous-move models as the Cournot quantity competition model and the Bertrand price competition model and the most popular sequential-move models as the Stackelberg model in which firms' quantities are sequentially chosen and the price leader-follower model, sequential-move models for mixed oligopolies have not been studied much. Pal [4], BàrcenaRuiz [5] and Matsumura and Ogawa [6] have studied the choice of price or quantity competition endogenously in a two-period mixed oligopoly model.
This paper studies an issue that seems to be very relevant to mixed oligopolies and yet remains unexplored as of now. While in symmetric private duopolies in which firms face symmetric demands and have equal production costs, which firm plays leader and the other the follower does not affect the market outcome and total welfare, it is unclear whether this conclusion continues to hold true for a mixed duopoly. The present paper studies and compares total welfare in sequential-move mixed duopoly models. There is a public firm whose objective is to maximize total welfare and a private firm that maximizes its own profit. The firms produce differentiated goods. Both quantity leader-follower models and price leader-follower models are examined.

Three main results are found in this study. First, which firm plays the leader and the other firm the follower matters to total welfare in a mixed duopoly. Second, if firms compete in quantity, then total welfare is higher if the private firm plays the leader, but if they compete in price, then total welfare is higher if the public firm plays the leader. Finally, total welfare is highest if firms compete in price with the public firm playing as the leader than if they compete in quantity with the private firm playing as the leader.

The above results are derived in the main text of the paper by assuming that the firms have the same unit cost 
of production. In Appendix, it is shown that these results continue to hold even if the firms have different levels of unit production cost. Hence, the findings here are independent of which firm is more efficient.

The rest of the paper is organized as follows. The next section introduces the basic model setup. Section 3 studies and compares total welfare under alternative quantity competition leader-follower models. Section 4 studies and compares total welfare under alternative price competition leader-follower models. A comparison of the two competition modes is also presented. Section 5 concludes the paper.

\section{Model Setup}

We consider a differentiated goods market with two firms (labeled as firm 1 and firm 2). Firm 1 is a public firm, while firm 2 is a private firm. The two firms face symmetric linear (inverse) demands:

$$
\begin{aligned}
& p_{1}=a-q_{1}-\gamma q_{2}, \\
& p_{2}=a-q_{2}-\gamma q_{1},
\end{aligned}
$$

where $p_{i}$ and $q_{i}(i=1,2)$ are the price and quantity of firm $i$ 's product, $a$ represents the maximum (nonnegative) price consumers are willing to pay for either good, and $\gamma \in$ $(0,1)$ measures the level of substitutability between the two products. The more independent two goods, are the smaller $\gamma$ is, and the closer the substitutes are the closer $\gamma$ is to 1 .

In the main text of the paper, we assume that firms produce at equal constant unit production cost $c(0 \leq c<a)$. In Appendix, we show that the main results of the paper continue to hold even if the two firms have different unit costs of production.

It is well known from Dixit [7] and Häckner [8] (see Hsu and Wang [9] for an extension) that the demand system (1) above corresponds to a representative consumer model with a quasi-linear utility function given by

$$
U\left(q_{1}, q_{2}\right)=a\left(q_{1}+q_{2}\right)-\frac{\left[\left(q_{1}\right)^{2}+\left(q_{2}\right)^{2}+2 \gamma q_{1} q_{2}\right]}{2} .
$$

The public firm l's objective function is total welfare, which is equal to total consumer surplus plus total firm profits and is given by

$$
W=U\left(q_{1}, q_{2}\right)-c\left(q_{1}+q_{2}\right) .
$$

The private firm 2's objective function is its profit, given by

$$
\Pi_{2}=\left(p_{2}-c\right) q_{2} .
$$

In the next two sections, we study alternative leaderfollower models under quantity competition (Section 3) and under price competition (Section 4) and compare the resulting total welfare levels.

\section{Alternative Quantity Leader-Follower Models}

Under quantity competition, the leader chooses its output first followed by output choice by the follower. Our alternative models correspond to the public firm 1 as the leader (Section 3.1) and the private firm 2 as the leader (Section 3.2).

3.1. Equilibrium with Public Firm as the Quantity Leader. Here, the private firm 2 is the quantity follower. We first find its best-response equation in quantity. Substituting the demand equation (1) for good 2 into (4) and maximizing with respect to $q_{2}$ yield firm 2's best-response as given by

$$
q_{2}=\frac{a-c-\gamma q_{1}}{2} .
$$

This response is the same as in the standard quantity leaderfollower game played by purely private firms. The quantity $q_{2}$ is a decreasing function of $q_{1}$ because quantities are strategic substitutes.

From the response relationship (5), we can find the leader firm l's optimal choice of output in the first stage of the game. More specifically, substituting (2) and (5) into total welfare (3) and maximizing give firm 1's optimal output. All relevant results for this model are summarized in the following lemma. Since derivations for the results in this lemma and all subsequent lemmas are straightforward, they are not provided in the paper but are available from the authors upon request.

Lemma 1. When the firms compete in quantity with the public firm 1 as the leader, the equilibrium is given by the following (superscript "1", here indicates that the public firm 1 is the leader).

(a) Prices are

$$
\begin{aligned}
& p_{1}^{1}=\frac{\gamma(1-\gamma) a+\left(4-\gamma-2 \gamma^{2}\right) c}{4-3 \gamma^{2}}, \\
& p_{2}^{1}=\frac{2(1-\gamma) a+\left(2+2 \gamma-3 \gamma^{2}\right) c}{4-3 \gamma^{2}} .
\end{aligned}
$$

(b) Quantities are

$$
\begin{aligned}
& q_{1}^{1}=\frac{(4-3 \gamma)(a-c)}{4-3 \gamma^{2}}, \\
& q_{2}^{1}=\frac{2(1-\gamma)(a-c)}{4-3 \gamma^{2}} .
\end{aligned}
$$

(c) Profits are

$$
\begin{gathered}
\Pi_{1}^{1}=\frac{\gamma(1-\gamma)(4-3 \gamma)(a-c)^{2}}{\left(4-3 \gamma^{2}\right)^{2}}, \\
\Pi_{2}^{1}=\frac{4(1-\gamma)^{2}(a-c)^{2}}{\left(4-3 \gamma^{2}\right)^{2}} .
\end{gathered}
$$


(d) Total welfare is

$$
W^{1}=\frac{(7-6 \gamma)(a-c)^{2}}{2\left(4-3 \gamma^{2}\right)} .
$$

3.2. Equilibrium with Private Firm as the Quantity Leader. Here the public firm 1 is the quantity follower. We first find its best-response equation in quantity. Substituting (2) into (3) and maximizing with respect to $q_{1}$ yield firm l's best-response in quantity as given by

$$
q_{1}=a-c-\gamma q_{2} .
$$

Comparing this response with that of the private firm's given in (5), the public firm is more responsive in that it wants to produce more output in response to any quantity choice by the private leader than a private firm would.

From the response relationship (10), we can find the leader firm 2's optimal choice of output in the first stage of the game. More specifically, substituting (10) into firm 2's profit (4) and maximizing give firm 2's optimal output. All relevant results for this model are summarized in the following lemma.

Lemma 2. When the firms compete in quantity with the private firm 2 as the leader, the equilibrium is given by the following (superscript " 2 " here indicates that firm 2 is the leader).

(a) Prices are

$$
p_{1}^{2}=c, \quad p_{2}^{2}=\frac{(1-\gamma) a+(1+\gamma) c}{2} .
$$

(b) Quantities are

$$
q_{1}^{2}=\frac{(2+\gamma)(a-c)}{2(1+\gamma)}, \quad q_{2}^{2}=\frac{a-c}{2(1+\gamma)} .
$$

(c) Profits are

$$
\Pi_{1}^{2}=0, \quad \Pi_{2}^{2}=\frac{(1-\gamma)(a-c)^{2}}{4(1+\gamma)} .
$$

(d) Total welfare is

$$
W^{2}=\frac{(7+\gamma)(a-c)^{2}}{8(1+\gamma)} .
$$

3.3. Comparison of Alternative Quantity Leader-Follower Models. Although we can make several comparisons based on the results in Lemmas 1 and 2, we will simply report the main result we seek to find out in this paper in the comparison of total welfare under alternative models. The following proposition reports the comparison result when the firms compete in quantity.

Proposition 3. Under quantity competition, total welfare is higher when the private firm 2 plays the leader and the public firm 1 plays the follower.
Proof. From Lemmas 1 and 2,

$$
\begin{aligned}
W^{1}-W^{2} & =\frac{(7-6 \gamma)(a-c)^{2}}{2\left(4-3 \gamma^{2}\right)}-\frac{(7+\gamma)(a-c)^{2}}{8(1+\gamma)} \\
& =-\frac{3 \gamma^{2}(1-\gamma)(a-c)^{2}}{8(1+\gamma)\left(4-3 \gamma^{2}\right)}<0 .
\end{aligned}
$$

The proposition follows immediately.

From this proposition, when firms compete in quantity, if the government wants to promote social welfare it should try to make the public firm a follower in the quantity leaderfollower game.

\section{Alternative Price Leader-Follower Models}

Under price competition, the leader chooses its price first followed by price choice by the follower. Our alternative models correspond to the public firm as the leader (Section 4.1) and the private firm as the leader (Section 4.2). For the derivations of this section, we need to provide the direct demand equations. Inverting the demand system (1) gives the equivalent demands as

$$
\begin{aligned}
& q_{1}=\frac{a}{1+\gamma}-\frac{1}{1-\gamma^{2}} p_{1}+\frac{\gamma}{1-\gamma^{2}} p_{2}, \\
& q_{2}=\frac{a}{1+\gamma}-\frac{1}{1-\gamma^{2}} p_{2}+\frac{\gamma}{1-\gamma^{2}} p_{1} .
\end{aligned}
$$

4.1. Equilibrium with Public Firm as the Price Leader. Here the private firm 2 is the price follower. We first find its bestresponse equation in price. Substituting the demand equation (16) for good 2 into (4) and maximizing with respect to $p_{2}$ yield firm 2's best-response in price as given by

$$
p_{2}=\frac{(1-\gamma) a+c+\gamma p_{1}}{2} .
$$

This response is the same as in the standard price leaderfollower model played by purely private firms. The price $p_{2}$ is an increasing function of $p_{1}$ because prices are strategic supplements.

From the response relationship (17), we can find the leader firm l's optimal choice of price in the first stage of the game. More specifically, substituting (2) and (17) into total welfare (3) and maximizing give firm l's optimal price. All relevant results for this model are summarized in the following lemma.

Lemma 4. When the firms compete in price with the public firm 1 as the leader, the equilibrium is given by the following (the additional superscript "*" here indicates that it is for the price competition model). 
(a) Prices are

$$
\begin{gathered}
p_{1}^{1 *}=\frac{\gamma(1-\gamma) a+\left(4-\gamma-2 \gamma^{2}\right) c}{4-3 \gamma^{2}} \\
p_{2}^{1 *}=\frac{(1-\gamma)\left(2-\gamma^{2}\right) a+\left(2+2 \gamma-2 \gamma^{2}-\gamma^{3}\right) c}{4-3 \gamma^{2}} .
\end{gathered}
$$

(b) Quantities are

$$
\begin{gathered}
q_{1}^{1 *}=\frac{\left(4+\gamma-3 \gamma^{2}-\gamma^{3}\right)(a-c)}{(1+\gamma)\left(4-3 \gamma^{2}\right)} \\
q_{2}^{1 *}=\frac{\left(2-\gamma^{2}\right)(a-c)}{(1+\gamma)\left(4-3 \gamma^{2}\right)}
\end{gathered}
$$

(c) Profits are

$$
\begin{gathered}
\Pi_{1}^{1 *}=\frac{\gamma(1-\gamma)\left(4+\gamma-3 \gamma^{2}-\gamma^{3}\right)(a-c)^{2}}{(1+\gamma)\left(4-3 \gamma^{2}\right)^{2}}, \\
\Pi_{2}^{1 *}=\frac{(1-\gamma)\left(2-\gamma^{2}\right)^{2}(a-c)^{2}}{(1+\gamma)\left(4-3 \gamma^{2}\right)^{2}} .
\end{gathered}
$$

(d) Total welfare is

$$
W^{1 *}=\frac{\left(7+\gamma-5 \gamma^{2}-\gamma^{3}\right)(a-c)^{2}}{2(1+\gamma)\left(4-3 \gamma^{2}\right)} .
$$

4.2. Equilibrium with Private Firm as the Price Leader. Here, the public firm 1 is the price follower. We first find its bestresponse equation in price. Substituting the demand equation (16) for good 1 into total welfare (3) and maximizing with respect to $p_{1}$ yield firm 1's best-response in price as given by

$$
p_{1}=(1-\gamma) c+\gamma p_{2} .
$$

Note that since $(1-\gamma) c<[(1-\gamma) a+c] / 2$, the public firm's response in price is not more aggressive than that of the private firm's given in (17). This reflects the public firm's interest in keeping the prices low.

From the response relationship (22), we can find the leader firm 2's optimal choice of price in the first stage of the game. More specifically, using (22), maximizing firm 2's profit (4), gives firm 2's optimal price. All relevant results for this model are summarized in the following lemma.

Lemma 5. When the firms compete in price with the private firm 2 as the leader, the equilibrium is given by the following.

(a) Prices are

$$
p_{1}^{2 *}=\frac{\gamma a+(2+\gamma) c}{2(1+\gamma)}, \quad p_{2}^{2 *}=\frac{a+(1+2 \gamma) c}{2(1+\gamma)} .
$$

(b) Quantities are

$$
q_{1}^{2 *}=\frac{a-c}{1+\gamma}, \quad q_{2}^{2 *}=\frac{a-c}{2(1+\gamma)} .
$$

(c) Profits are

$$
\Pi_{1}^{2 *}=\frac{\gamma(a-c)^{2}}{2(1+\gamma)^{2}}, \quad \Pi_{2}^{2 *}=\frac{(a-c)^{2}}{4(1+\gamma)^{2}} .
$$

(d) Total welfare is

$$
W^{2 *}=\frac{(7+8 \gamma)(a-c)^{2}}{8(1+\gamma)^{2}} .
$$

4.3. Comparison of Alternative Price Leader-Follower Models. The following proposition reports the comparison result in total welfare when the firms compete in price.

Proposition 6. Under price competition, total welfare is higher when the public firm 1 plays the leader and the private firm 2 plays the follower.

Proof. From Lemmas 4 and 5,

$$
\begin{aligned}
W^{1 *}-W^{2 *}= & \frac{\left(7+\gamma-5 \gamma^{2}-\gamma^{3}\right)(a-c)^{2}}{2(1+\gamma)\left(4-3 \gamma^{2}\right)} \\
& -\frac{(7+8 \gamma)(a-c)^{2}}{8(1+\gamma)^{2}} \\
= & \frac{\gamma^{2}\left(5-4 \gamma^{2}\right)(a-c)^{2}}{8(1+\gamma)^{2}\left(4-3 \gamma^{2}\right)}>0 .
\end{aligned}
$$

The proposition follows immediately.

From this proposition, when firms compete in price, if the government wants to promote social welfare it should try to make the public firm the leader in the price leader-follower game.

Finally, a comparison of the results under both quantity and price competition can reveal which competition mode leads to higher total welfare, when firms make their choices sequentially. This result is summarized in the next proposition.

Proposition 7. Total welfare is highest when firms compete in price with the public firm playing the leader and the private firm the follower.

Proof. By Propositions 3 and 6, we need only to compare the total welfare under price competition with the public firm as the leader and that under quantity competition with the private firm as the leader. The difference in total welfare of concern here is given by

$$
\begin{aligned}
W^{1 *}-W^{2}= & \frac{\left(7+\gamma-5 \gamma^{2}-\gamma^{3}\right)(a-c)^{2}}{2(1+\gamma)\left(4-3 \gamma^{2}\right)} \\
& -\frac{(7+\gamma)(a-c)^{2}}{8(1+\gamma)}=\frac{\gamma^{2}(1-\gamma)(a-c)^{2}}{8(1+\gamma)\left(4-3 \gamma^{2}\right)}>0,
\end{aligned}
$$

from which follows the proposition. 
Hence, if the government can influence the nature of competition (between price and quantity), it will try to make firms compete in price and make the public firm the leader in the price leader-follower game.

\section{Conclusion}

Using a simple differentiated goods linear demand framework, this paper has studied and compared total welfare in a mixed duopoly with sequential moves. Both quantity leader-follower models and price leader-follower models are considered. It is found that total welfare is affected by which firm is the leader and whether firms compete in quantity or price.

\section{Appendix}

In this appendix, we extend the analyses in the text by allowing the two firms to have different levels of unit costs of production. Let $c_{i}$ denote the constant unit production cost of firm $i(i=1,2)$. In the following, we present the counterparts of the four lemmas in the text. They correspond to the four relevant scenarios: leader-follower model with the public firm 1 as leader under quantity competition, leader-follower model with the private firm 2 as leader under quantity competition, leader-follower model with the public firm 1 as leader under price competition, and leader-follower model with the private firm 2 as leader under price competition.

We start with the quantity competition models. The firms' best-responses in quantity as follower are now given by

$$
\begin{aligned}
& q_{2}=\frac{a-c_{2}-\gamma q_{1}}{2}, \\
& q_{1}=a-c_{1}-\gamma q_{2} .
\end{aligned}
$$

Applying the same procedures introduced in the text, we obtain the following lemmas regarding the quantity competition leader-follower models.

Lemma A.1. When the firms compete in quantity with the public firm 1 as the leader, the equilibrium is given by the following.

(a) Prices are

$$
\begin{aligned}
& p_{1}^{1}=\frac{\gamma(1-\gamma) a+2\left(2-\gamma^{2}\right) c_{1}-\gamma c_{2}}{4-3 \gamma^{2}}, \\
& p_{2}^{1}=\frac{2(1-\gamma) a+2 \gamma c_{1}+\left(2-3 \gamma^{2}\right) c_{2}}{4-3 \gamma^{2}} .
\end{aligned}
$$

(b) Quantities are

$$
\begin{aligned}
& q_{1}^{1}=\frac{(4-3 \gamma) a-4 c_{1}+3 \gamma c_{2}}{4-3 \gamma^{2}}, \\
& q_{2}^{1}=\frac{2\left[(1-\gamma) a+\gamma c_{1}-c_{2}\right]}{4-3 \gamma^{2}} .
\end{aligned}
$$

(c) Profits are

$$
\begin{gathered}
\Pi_{1}^{1}=\frac{\gamma\left[(1-\gamma) a+\gamma c_{1}-c_{2}\right]\left[(4-3 \gamma) a-4 c_{1}+3 \gamma c_{2}\right]}{\left(4-3 \gamma^{2}\right)^{2}}, \\
\Pi_{2}^{1}=\frac{4\left[(1-\gamma) a+\gamma c_{1}-c_{2}\right]^{2}}{\left(4-3 \gamma^{2}\right)^{2}} .
\end{gathered}
$$

(d) Total welfare is

$$
\begin{aligned}
W^{1}= & \left((7-6 \gamma) a^{2}-2\left(4 c_{1}+3 c_{2}\right) a\right. \\
& \left.+6 \gamma\left(c_{1}+c_{2}\right) a+4\left(c_{1}\right)^{2}+3\left(c_{2}\right)^{2}-6 \gamma c_{1} c_{2}\right) \\
\times & \left(2\left(4-3 \gamma^{2}\right)\right)^{-1} .
\end{aligned}
$$

Lemma A.2. When the firms compete in output with the private firm 2 as the leader, the equilibrium is given by the following.

(a) Prices are

$$
p_{1}^{2}=c_{1}, \quad p_{2}^{2}=\frac{(1-\gamma) a+\gamma c_{1}+c_{2}}{2} .
$$

(b) Quantities are

$$
\begin{gathered}
q_{1}^{2}=\frac{\left(2-\gamma-\gamma^{2}\right) a-\left(2-\gamma^{2}\right) c_{1}+\gamma c_{2}}{2\left(1-\gamma^{2}\right)}, \\
q_{2}^{2}=\frac{(1-\gamma) a+\gamma c_{1}-c_{2}}{2\left(1-\gamma^{2}\right)} .
\end{gathered}
$$

(c) Profits are

$$
\Pi_{1}^{2}=0, \quad \Pi_{2}^{2}=\frac{\left[(1-\gamma) a+\gamma c_{1}-c_{2}\right]^{2}}{4\left(1-\gamma^{2}\right)} .
$$

(d) Total welfare is

$$
\begin{aligned}
W^{2}= & \left(\left(7-6 \gamma-\gamma^{2}\right) a^{2}-2\left(4 c_{1}+3 c_{2}-3 \gamma c_{1}-3 \gamma c_{2}-\gamma^{2} c_{1}\right)\right. \\
& \left.\times a+\left(4-\gamma^{2}\right)\left(c_{1}\right)^{2}+3\left(c_{2}\right)^{2}-6 \gamma c_{1} c_{2}\right) \\
& \times\left(8\left(1-\gamma^{2}\right)\right)^{-1} .
\end{aligned}
$$

From Lemmas A.1 and A.2,

$$
W^{1}-W^{2}=-\frac{3 \gamma^{2}\left[(1-\gamma) a+\gamma c_{1}-c_{2}\right]^{2}}{8\left(1-\gamma^{2}\right)\left(4-3 \gamma^{2}\right)}<0 .
$$

This confirms that the result in Proposition 3 continues to hold when the two firms have differing unit costs of production. 
We next work with the price competition models. The firms' best-responses in price as follower are now given by

$$
\begin{gathered}
p_{2}=\frac{(1-\gamma) a+c_{2}+\gamma p_{1}}{2}, \\
p_{1}=c_{1}-\gamma c_{2}+\gamma p_{2} .
\end{gathered}
$$

Applying the same procedures introduced in the text, we obtain the following lemmas regarding the price competition leader-follower models.

Lemma A.3. When the firms compete in price with the public firm 1 as the leader, the equilibrium is given by the following.

(a) Prices are

$$
\begin{gathered}
p_{1}^{1 *}=\frac{\gamma(1-\gamma) a+2\left(2-\gamma^{2}\right) c_{1}-\gamma c_{2}}{4-3 \gamma^{2}}, \\
p_{2}^{1 *}=\frac{(1-\gamma)\left(2-\gamma^{2}\right) a+\gamma\left(2-\gamma^{2}\right) c_{1}+2\left(1-\gamma^{2}\right) c_{2}}{4-3 \gamma^{2}} .
\end{gathered}
$$

(b) Quantities are

$$
\begin{aligned}
& q_{1}^{1 *}=\left(\left(4-3 \gamma-4 \gamma^{2}+2 \gamma^{3}+\gamma^{4}\right) a\right. \\
&\left.-\left(2-\gamma^{2}\right)^{2} c_{1}+\gamma\left(3-2 \gamma^{2}\right) c_{2}\right) \\
& \times\left(\left(1-\gamma^{2}\right)\left(4-3 \gamma^{2}\right)\right)^{-1}, \\
& q_{2}^{1 *}=\frac{\left(2-\gamma^{2}\right)(a-c)}{(1+\gamma)\left(4-3 \gamma^{2}\right)} .
\end{aligned}
$$

(c) Profits are

$$
\begin{aligned}
\Pi_{1}^{1 *}= & \left(\gamma\left[(1-\gamma) a+\gamma c_{1}-c_{2}\right]\right. \\
\times & {\left[\left(4-3 \gamma-4 \gamma^{2}+2 \gamma^{3}+\gamma^{4}\right) a\right.} \\
& \left.\left.\quad-\left(2-\gamma^{2}\right)^{2} c_{1}+\gamma\left(3-2 \gamma^{2}\right) c_{2}\right]\right) \\
\times & \left(\left(1-\gamma^{2}\right)\left(4-3 \gamma^{2}\right)^{2}\right)^{-1} \\
\Pi_{2}^{1 *}= & \frac{\left(2-\gamma^{2}\right)^{2}\left[(1-\gamma) a+\gamma c_{1}-c_{2}\right]^{2}}{\left(1-\gamma^{2}\right)\left(4-3 \gamma^{2}\right)^{2}} .
\end{aligned}
$$

(d) Total welfare is

$$
\begin{aligned}
W^{1 *}=( & \left(7-6 \gamma-6 \gamma^{2}+4 \gamma^{3}+\gamma^{4}\right) a^{2}+2(1-\gamma) \\
& \times\left[\left(-4-\gamma+3 \gamma^{2}+\gamma^{3}\right) c_{1}-\left(3-2 \gamma^{2}\right) c_{2}\right] a \\
& +\left(2-\gamma^{2}\right)^{2}\left(c_{1}\right)^{2}+\left(3-2 \gamma^{2}\right)\left(c_{2}\right)^{2} \\
& \left.-2 \gamma\left(3-2 \gamma^{2}\right) c_{1} c_{2}\right) \\
\times & \left(2\left(1-\gamma^{2}\right)\left(4-3 \gamma^{2}\right)\right)^{-1} .
\end{aligned}
$$

Lemma A.4. When the firms compete in price with the private firm 2 as the leader, the equilibrium is given by the following.

(a) Prices are

$$
\begin{aligned}
& p_{1}^{2 *}=\frac{\gamma(1-\gamma) a+\left(2-\gamma^{2}\right) c_{1}-\gamma c_{2}}{2\left(1-\gamma^{2}\right)}, \\
& p_{2}^{2 *}=\frac{(1-\gamma) a+\gamma c_{1}+\left(1-2 \gamma^{2}\right) c_{2}}{2\left(1-\gamma^{2}\right)} .
\end{aligned}
$$

(b) Quantities are

$$
q_{1}^{2 *}=\frac{(1-\gamma) a-c_{1}+\gamma c_{2}}{1-\gamma^{2}}, \quad q_{2}^{2 *}=\frac{(1-\gamma) a+\gamma c_{1}-c_{2}}{2\left(1-\gamma^{2}\right)} .
$$

(c) Profits are

$$
\begin{gathered}
\Pi_{1}^{2 *}=\frac{\gamma\left[(1-\gamma) a-c_{1}+\gamma c_{2}\right]\left[(1-\gamma) a+\gamma c_{1}-c_{2}\right]}{2\left(1-\gamma^{2}\right)^{2}}, \\
\Pi_{2}^{2 *}=\frac{\left[(1-\gamma) a+\gamma c_{1}-c_{2}\right]^{2}}{4\left(1-\gamma^{2}\right)^{2}} .
\end{gathered}
$$

(d) Total welfare is

$$
\begin{aligned}
W^{2 *}= & \left(\left(7-6 \gamma-9 \gamma^{2}+8 \gamma^{3}\right) a^{2}+2(1-\gamma)\right. \\
& \times\left[\left(-4-\gamma+4 \gamma^{2}\right) c_{1}-\left(3-4 \gamma^{2}\right) c_{2}\right] a+\left(4-5 \gamma^{2}\right) \\
& \left.\times\left(c_{1}\right)^{2}+\left(3-4 \gamma^{2}\right)\left(c_{2}\right)^{2}-2 \gamma\left(3-4 \gamma^{2}\right) c_{1} c_{2}\right) \\
& \times\left(8\left(1-\gamma^{2}\right)^{2}\right)^{-1} .
\end{aligned}
$$

From Lemmas A.3 and A.4,

$$
W^{1 *}-W^{2 *}=\frac{\gamma^{2}\left(5-4 \gamma^{2}\right)\left[(1-\gamma) a+\gamma c_{1}-c_{2}\right]^{2}}{8\left(1-\gamma^{2}\right)^{2}\left(4-3 \gamma^{2}\right)}>0 .
$$

This confirms that the result in Proposition 6 continues to hold when the two firms have differing unit costs of production.

Finally, we compare the total welfare under price competition with the public firm as the leader and that under quantity competition with the private firm as the leader. From the results above, the difference in total welfare of concern here is given by

$$
W^{1 *}-W^{2}=\frac{\gamma^{2}\left[(1-\gamma) a+\gamma c_{1}-c_{2}\right]^{2}}{8\left(1-\gamma^{2}\right)\left(4-3 \gamma^{2}\right)}>0 .
$$

It follows that the result in Proposition 7 also continues to hold when the two firms have differing unit costs of production. 


\section{References}

[1] W. Merril and N. Schneider, "Government firms in oligopoly industries: a short run analysis," Quarterly Journal of Economics, vol. 80, pp. 400-412, 1966.

[2] T. Matsumura, "Partial privatization in mixed duopoly," Journal of Public Economics, vol. 70, no. 3, pp. 473-483, 1998.

[3] G. De Fraja and F. Delbono, "Game theoretic models of mixed oligopoly," Journal of Economic Surveys, vol. 4, pp. 1-17, 1989.

[4] D. Pal, "Endogenous timing in a mixed oligopoly," Economics Letters, vol. 61, no. 2, pp. 181-185, 1998.

[5] J. C. Bárcena-Ruiz, "Endogenous timing in a mixed duopoly: price competition," Journal of Economics, vol. 91, no. 3, pp. 263$272,2007$.

[6] T. Matsumura and A. Ogawa, "Price versus quantity in a mixed duopoly," Economics Letters, vol. 116, no. 2, pp. 174-177, 2012.

[7] A. Dixit, "A model of duopoly suggesting a theory of entry barriers," Bell Journal of Economics, vol. 10, pp. 20-32, 1979.

[8] J. Häckner, "A note on price and quantity competition in differentiated oligopolies," Journal of Economic Theory, vol. 93, no. 2, pp. 233-239, 2000.

[9] J. Hsu and X. H. Wang, "On welfare under Cournot and Bertrand Competition in differentiated oligopolies," Review of Industrial Organization, vol. 27, no. 2, pp. 185-191, 2005. 


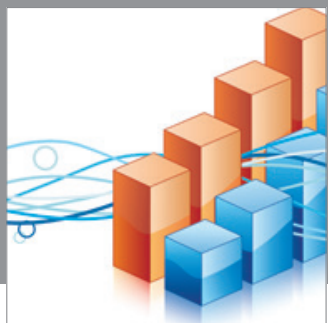

Advances in

Operations Research

mansans

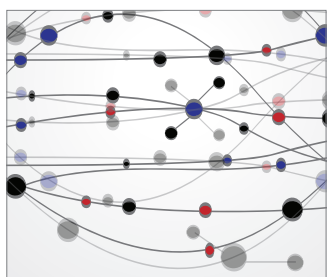

The Scientific World Journal
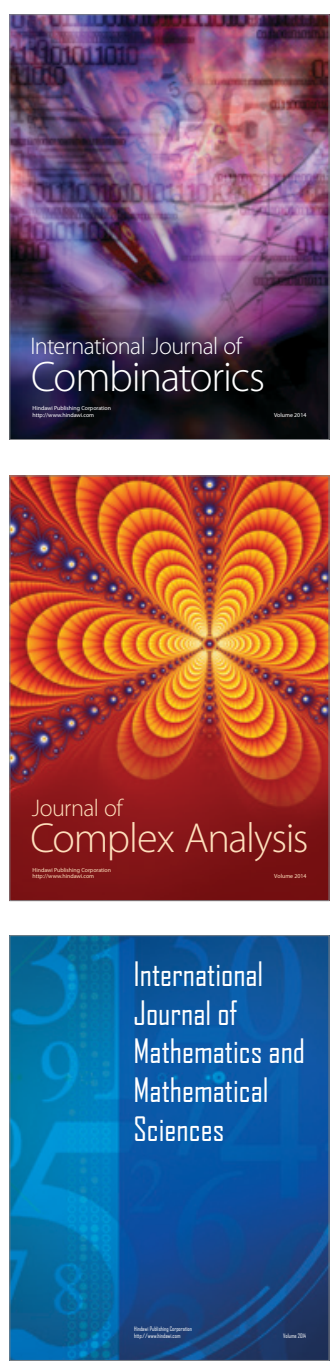
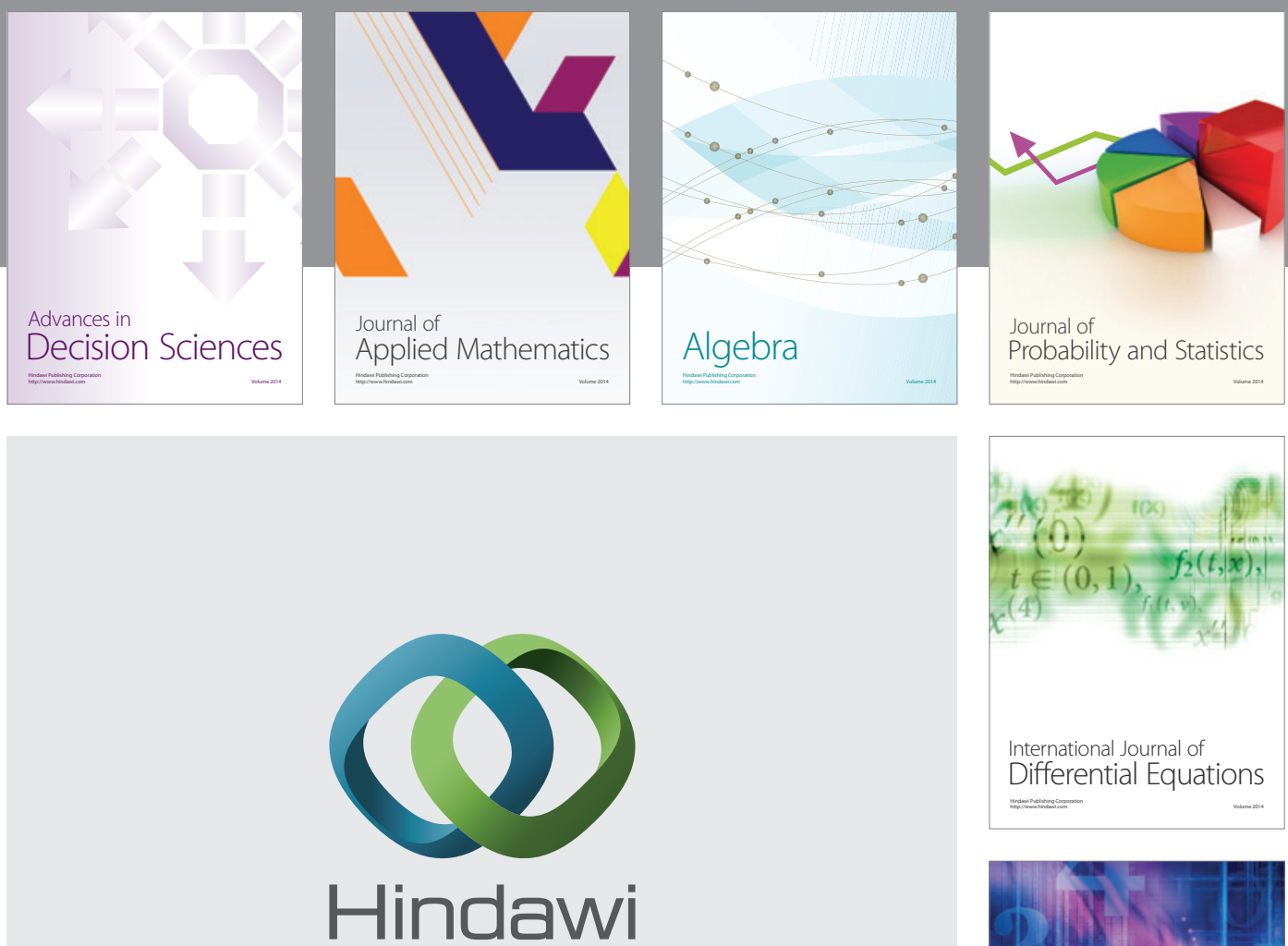

Submit your manuscripts at http://www.hindawi.com
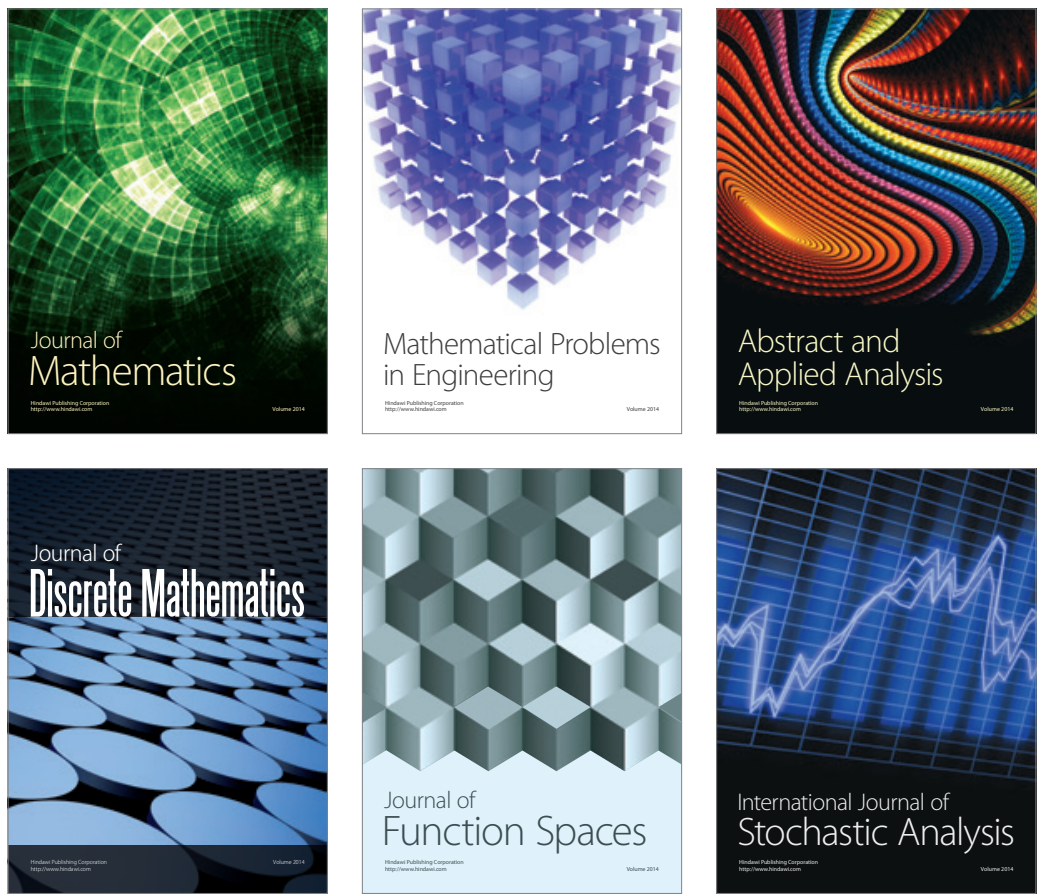

Journal of

Function Spaces

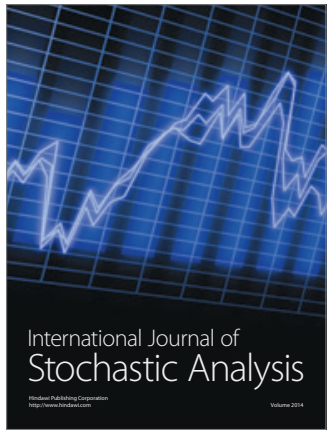

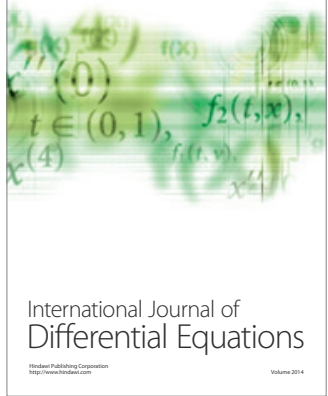
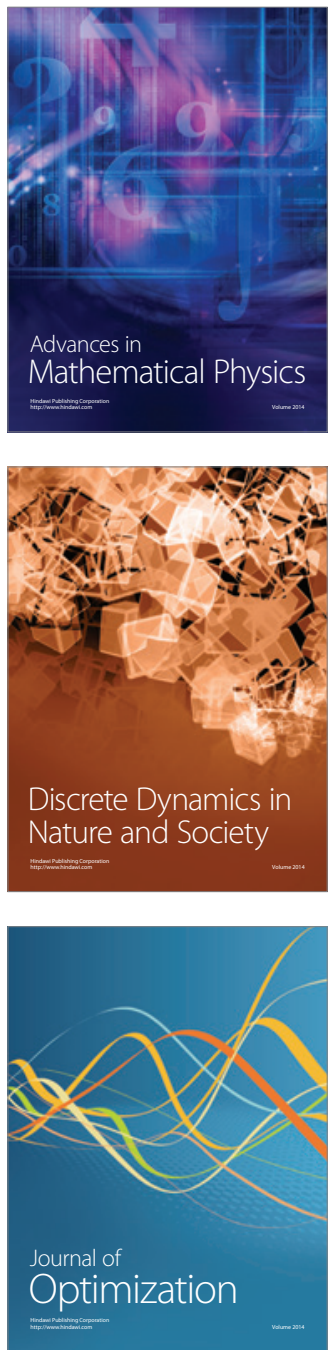